\title{
OUTCOME OF TRANSORAL ENDOSCOPIC THYROIDECTOMY VESTIBULAR APPROACH (TOETVA) IN COMPARISON WITH OPEN THYROIDECTOMY FOR BENIGN THYROID NODULES
}

\author{
Sadq Ghaleb Kadem*, Sabah Abdulsahb Mohamd ${ }^{@}$ \& Zainab Taher Ibrahim ${ }^{\#}$ \\ *MB,ChB, FICMS, Consultant General Surgeon, Department of Surgery, Al-Shiffa General Hospital. \\ ${ }^{\circledR}$ MBChB, Specialist ENT Surgeon, Department of Surgery, Al-Shiffa General Hospital, Basrah. \\ "MB,ChB, CABS, Specialist Radiologist, Department of Radiology, Al-Sadr Teaching Hospital, Basrah, \\ IRAQ.
}

\begin{abstract}
Open thyroidectomy; is the gold standard surgical procedure for thyroid diseases, but the incision scar in the anterior aspect of the neck due to this approach cannot be avoided and may results in a permanent cosmetic defect. Therefore, there is a need to improve postoperative quality of life, including cosmetics. Recently, transoral endoscopic thyroidectomy has been developed; it is a natural orifice thyroid surgery, minimally invasive and completely scar free.

This study aimed to describe the outcome, patient's satisfaction, and complications after hemithyroidectomy for benign thyroid nodules by transoral endoscopic vestibular approach in comparison with open approach. This study was conducted in Al-Shiffa General hospital, Basrah, Iraq from August 2017 to June 2019 and was approved by a local ethical committee.

Fifty patients with benign thyroid nodules who are candidate for hemithyroidectomy were included in the study; they were divided into two groups according to the method for thyroidectomy which was either conventional open or transoral endoscopic thyroidectomy vestibular approach based on the patients' preferences. All operations were performed by the same surgical team.

The results of this study showed that $24(48 \%)$ of them operated upon by transoral endoscopic thyroidectomy vestibular approach, while the remaining $26(52 \%)$ patients have been operated upon by open thyroidectomy approach. Transoral endoscopic thyroidectomy vestibular approach reported significant longer operative time, has comparable rate of complications with an excellent cosmetic outcome and better postoperative patients' satisfaction in comparison to open thyroidectomy.

In conclusion, transoral endoscopic thyroidectomy vestibular approach is a safe and feasible procedure with an excellent cosmetic outcome and better patients' satisfaction. At present, it is a relatively time-consuming procedure and, therefore, candidate patients with a strong motivation for scar free surgery are recommended.

Key words: Thyroidectomy; Endoscopic thyroidectomy; Transoral thyroidectomy; Benign, Nodule
\end{abstract}

\section{Introduction}

$\mathrm{T}$ hyroid nodules are common in general population with $3-7 \%$ prevalence ${ }^{1}$. The prevalence increases to $19-67 \%$ by using high-resolution ultrasonography among randomly selected individuals ${ }^{2}$. About $5-15 \%$ of thyroid nodules are malignant ${ }^{3}$.

Based on the 2015 American Thyroid Association guidelines, most of benign thyroid nodules can be observed safely without surgery ${ }^{4}$. Indications for surgical treatment in benign thyroid nodules are; indeterminate or suspicious fine needle aspiration cytology for malignancy, compressive signs and symptoms, excessive thyroid hormone producing nodule, and patient preference in case of thyroid nodule producing visible mass in the neck ${ }^{5}$.

Open thyroidectomy is the gold standard surgical treatment for thyroid diseases, but the incision scar in the anterior aspect of the neck due to this approach cannot be avoided and may results in a permanent 
cosmetic defect ${ }^{6}$. Therefore, the need to improve postoperative quality of life, including cosmetics, has increased ${ }^{7}$.

Gagner M, in 1996, reported feasibility of endoscopic approach to the parathyroid glands ${ }^{8}$. After that, a number of techniques simultaneously started being called as minimally invasive thyroid surgery. These can be classified as pure endoscopic techniques and video-assisted techniques. All these methods still leaving a scar in the endoscopic port's site entry; in the neck, axilla, breast or chest wall ${ }^{9-11}$.

Recently, Transoral endoscopic thyroidectomy has been developed; it is a natural orifice thyroid surgery, minimally invasive and completely scar free ${ }^{12-15}$. The refinement of this transoral thyroidectomy technique was wellestablished and described by Anuwong A, as the transoral endoscopic thyroidectomy vestibular approach (TOETVA) with excellent clinical results ${ }^{16}$. In a systemic review of 15 studies; TOETVA have a comparable rate of complications to that of conventional open thyroidectomy, but unfortunately this new approach may be associated with new complications; mental nerve palsy, cervical and/or mediastinal emphysema, conversion to open thyroidectomy, and because it is a clean contaminated surgery, it may be associated with an increase rate of deepseated neck infection, although the reported incidence of these complications was rare, they are considered as an additional complications added to the field of thyroid surgery ${ }^{17}$.

Currently accepted patient selection criteria for TOETVA are; strong motivation for scar free surgery, thyroid gland diameter $\leq 10 \mathrm{~cm}$ or dominant nodule diameter $\leq 5 \quad \mathrm{~cm}$ in ultrasonography, a benign disease as (thyroid cyst or nodular goiter), follicular neoplasm, micropapillary thyroid cancer or differentiated thyroid cancer $\leq 2 \mathrm{~cm}$ without lymph node metastasis or extrathyroidal extension ${ }^{18,19}$.
In this study we describe the outcome, patient's satisfaction, and complications after hemithyroidectomy for benign thyroid nodules by transoral endoscopic vestibular approach in comparison with open approach.

\section{Patients and Methods}

This study was conducted in Al-Shiffa General hospital, Basrah, Iraq from August 2017 to June 2019 and was approved by a local ethical committee. Fifty patients with benign thyroid nodules who are candidates for hemithyroidectomy were included in the study and were divided into two groups according to the method of thyroidectomy which was either conventional open (OT group) or TOETVA (ET group) based on the patients' preferences. All participants were provided with the particular details for their surgeries and only patients with strong motivation for scar free surgery were selected for TOETVA procedure. Informed consent was obtained from each patient. All patients were operated upon by the same surgical team.

Inclusion criteria included; female patients with unilateral thyroid nodularity (solitary or dominant thyroid nodule) with a diameter less than $5 \mathrm{~cm}$, FNA (Bethesda II), BMI less than 30 with no hyperthyroidism, no thyroiditis, no history of previous thyroid surgery or neck irradiation, and have postoperative follow-up period $\geq 12$ weeks.

\section{Operative techniques:}

All patients were admitted to the hospital one day pre-surgery for routine investigations and preparation for general anesthesia. A flexible fiber-optic laryngoscopy was performed to confirm normal recurrent laryngeal nerve function. During induction of general anesthesia with endotracheal intubation through the mouth, the patient was put in supine position with the neck extended. Patient received intravenous prophylactic antibiotics, either amoxicillin (1 g) or 
clindamycin (900 $\mathrm{mg}$ ) in cases of an allergy to penicillin.

The surgical approach of TOETVA, followed the operative steps described by Anuwong $\mathrm{A}^{16}$ as shown in Figure 1. Following washing of the oral cavity with diluted povidone iodine and normal saline, a $10 \mathrm{~mm}$ transverse vestibular incision was made in the midline and extended in depth up to the mandible symphysis [Figure 1A]. Using a Verse needle, sub-platysmal hydrodissection with approximately $20 \mathrm{~mL}$ of normal saline with adrenaline $(500 \mathrm{~mL}$ normal saline $+1 \mathrm{~mL}$ adrenaline) was performed in three axes (central, right and left) [Figure 1B]. Blunt dissection of the subplatysmal plane with a blunt dilator was performed in the same three axes as the hydrodissection [Figure 1C]. A $10 \mathrm{~mm}$ central trocar for the camera was placed through the vestibular incision and insufflation was performed up to 5-6 $\mathrm{mmHg}$ with carbon dioxide [Figure 1D]. Two additional $5 \mathrm{~mm}$ trocars were placed under direct vision through two $5 \mathrm{~mm}$ vertical incisions in the most lateral aspects of either side of the vestibule nearest to the edges of the mouth [Figure $1 E]$. Using an ultrasonic energy device SONICBEAT, USG 400 (Olympus, Tokyo, Japan) to dissect and divide the tissue and blood vessels. The peritracheal fascia was divided in the midline as in open thyroidectomy approach. Using a hanging sutures passing through the skin, the strap muscles were retracted laterally. The thyroid isthmus was dissected and transected. All thyroid blood vessels were divided as close to the thyroid as possible. Intraoperative neuromonitoring for the recurrent laryngeal nerve is not practised in Al-Shifaa General Hospital and therefore, anatomical landmarks were used to identify and preserve this nerve.

Parathyroid glands were identified and preserved. After complete excision of thyroid lobe, the specimen was removed using an endobag via the $10 \mathrm{~mm}$ vestibular incision and sent for histopathology analysis.

Closure of the peritracheal fascia was performed using absorbable sutures and the vestibular wounds were closed in two layers with absorbable sutures.
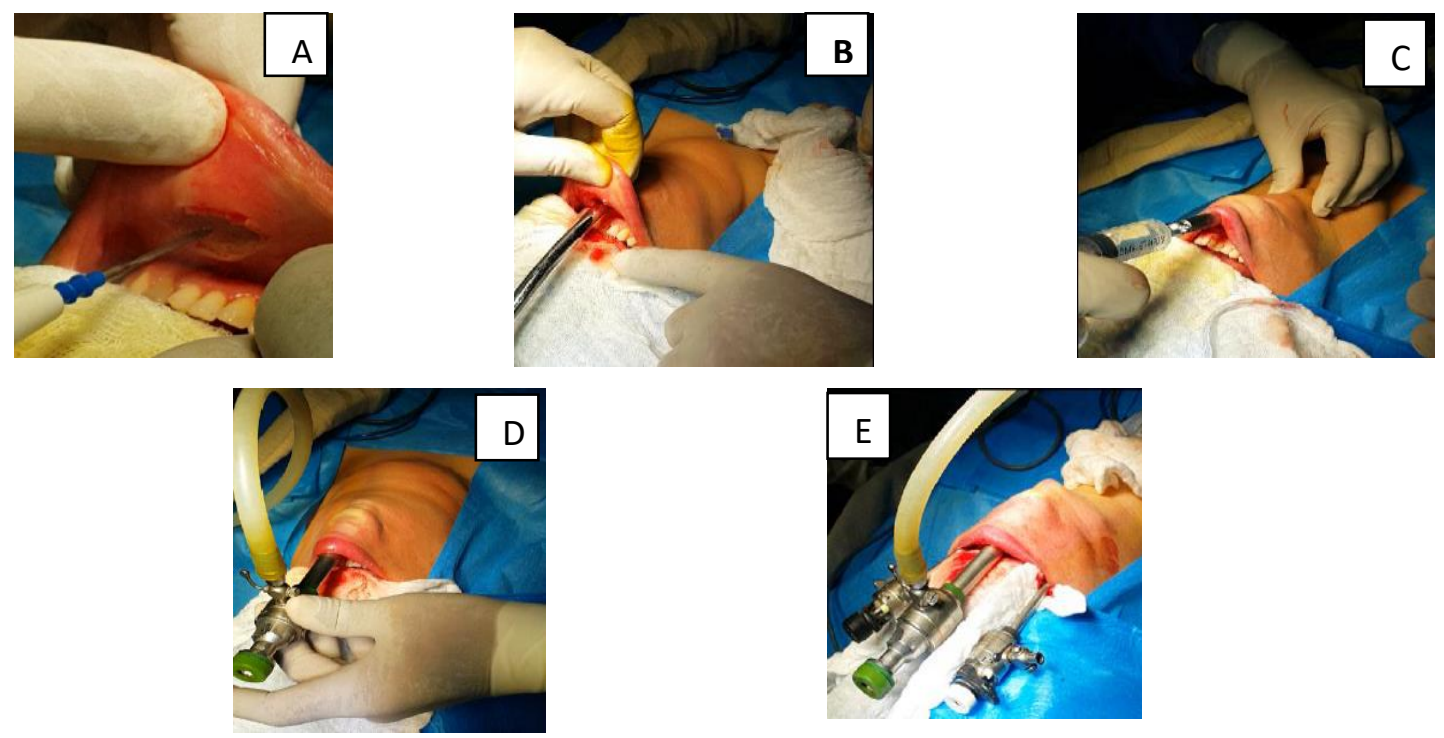

Figure 1: Photographs of the surgical procedure steps. A: Transverse vestibular incision (10 $\mathrm{mm}$ ) was made in the midline and extended to the mandible symphysis. B: Sub-platysmal hydrodissection was performed on three axes. C: Blunt dissection of the sub-platysmal plane with a blunt dilator on the same three axes as the hydrodissection. D: A $10 \mathrm{~mm}$ central trocar for the camera was placed through the vestibular incision and carbon dioxide insufflation was done. E: Two additional $5 \mathrm{~mm}$ trocars were placed through vertical incisions in the most lateral aspects of either side of the vestibule nearest to the edges of the mouth. 
In patients subjected to conventional open thyroidectomy; a collar skin incision done mid-way between suprasternal notch and thyroid notch and extended from one sternomastoid muscle to another, creation of subplatismal flaps, vertical incision of pretracheal facia and separation of strap muscles and mobilization of thyroid lobe. Using an ultrasonic energy device SONICBEAT, USG 400 (Olympus, Tokyo, Japan) for sealing and division of blood vessels and for dissection and excision of thyroid lobe. At the end of the procedure; the wound closed in layers.

During removal of the endotracheal tube, the vocal cords were re-examined with flexible fibreoptic laryngoscopy to confirm normal function of the recurrent laryngeal nerve. Following recovery from anesthesia, patients were transferred to the surgical ward for observation, all patients were given analgesia in form of Diclofenac injection (75mg IM) shortly after reaching the surgical ward, after that all patients were re-evaluated at the night tour and only patients with pain were given analgesia in form of Tramadol injection (50mg IM).

The visual analogue scale (VAS) was used for postoperative pain assessment (0 to 10 scale); no pain=0, mild pain $=1-3$, moderate pain $=4-6$ and severe pain $=7-10$. The pain assessment have been done by the same resident doctor during the night tour and then during the morning tour of the first postoperative day.

Intravenous antibiotics were continued until the patients were discharged from hospital.

The patients were discharged from hospital when the vital signs are within normal range; the patient could manage an oral diet and had been given instructions to continue oral antibiotics and mouthwash (in case of TOETVA patient) for one week. Patients were reexamined at the end of the first postoperative week, then after four, eight and twelve weeks, at which time flexible fibreoptic laryngoscopy was again performed to evaluate vocal cord function and ultrasound examination of cervical region performed to evaluate seroma and hematoma formation. At the end of follow-up period, the Arabic version of 36-Item Short Form Health Survey (SF36 questionnaire) was used to assess the patient's satisfaction and burden of surgery on quality of life ${ }^{20}$.

The following domains were evaluated via an in-clinic interview: physical functioning; bodily pain; general health; vitality; social functioning; roleemotional; mental health.

The following data were recorded perioperatively: patients' demographics, clinical diagnosis, preoperative thyroid ultrasound findings, postoperative cervical region ultrasound findings, histopathology results, and flexible fiberoptic laryngoscopy for vocal cord examination before and after operation. In addition, surgical procedure details and outcome such as duration of surgery in minutes (calculated from start of skin or mucous membrane incision to end of wound closure), results of the visual analogue scale (VAS) for postoperative pain assessment, results of SF-36 questionnaire for patients satisfaction and quality of life after surgery and length of hospital stay (hour) were also documented. Postoperative complications such as recurrent laryngeal nerve palsy, symptoms of hypocalcemia (paraesthesia, muscle spasm, and Chvostek's or Trousseau's signs, confirmed by serum calcium $<2.1 \mathrm{mmol} / \mathrm{ml}$ ), seroma or hematoma formation, bleeding necessitates blood transfusion and/or reoperation, symptoms of mental nerve palsy (loss of sensation over the lower lip), cervical and/or mediastinal emphysema, conversion to open thyroidectomy, deep-seated neck infection, and any intraoperative or postoperative mortality was also documented. IBM SPSS Version 20 (IBM Corp., Armonk, NY, USA) was used for 
data analysis. Results were directly compared between the two groups using the two-tailed t-test for quantitative variables and related samples. The McNemar test was used for qualitative variables. The statistical significance was considered at $\mathrm{P}<0.05$. Patients' age, surgery duration (min), hospital stay duration (hour), drainage volume (ml), and drain removal time (hour) were expressed in mean $\pm \mathrm{SD}$. Other patient's characteristics such as gender and various complications were expressed in frequencies.

\section{Results}

The total number of hemithyroidectomies that performed in this study were 50 cases; 24 (48\%) of them have been operated with TOETVA (ET group), while the remaining $26(52 \%)$ patients have been operated with open approach (OT group). The patient's characteristics of both groups are shown in table I.

Table I: Patients characteristics.

\begin{tabular}{|l|l|l|l|}
\hline Patients characteristics & ET group (N=24) & OT group (N=26) & P-Value \\
\hline Mean age (y) \pm SD & $27.34 \pm 8.34$ & $34.23 \pm 7.45$ & 0.003 \\
\hline Gender (\%) & 0 & 0 & \\
\hline $\begin{array}{l}\text { Male } \\
\text { Female } \\
\text { Total }\end{array}$ & $24(100 \%)$ & $26(100 \%)$ & 1.000 \\
\hline Body mass index BMI $(\%)$ & $26(100 \%)$ & \\
\hline $16-18.5$ & $7(29.166 \%)$ & $6(23.076 \%)$ & 0.781 \\
$>18.5-25$ & $12(50 \%)$ & $13(50 \%)$ & 0.841 \\
$>25-30$ & $5(20.834 \%)$ & $7(26.924 \%)$ & 0.563 \\
Total & $24(100 \%)$ & $26(100 \%)$ & \\
\hline Laterality of thyroid nodule (\%) & $14(53.846 \%)$ & 0.715 \\
\hline $\begin{array}{l}\text { Right side nodule } \\
\text { Left side nodule }\end{array}$ & $16(66.666 \%)$ & $12(46.154 \%)$ & 0.371 \\
Total & $8(33.334 \%)$ & $26(100 \%)$ & 0.204 \\
\hline $\begin{array}{l}\text { Mean size of thyroid } \\
\text { nodule (cm) } \pm \text { SD }\end{array}$ & $3.6 \pm 0.443$ & $3.8 \pm 0.632$ & \\
\hline
\end{tabular}

Regarding the outcome of both procedures, the patients operated upon with endoscopic procedure (ET group) reported longer mean duration of surgery in comparison to (OT group) (93 \pm 8.34 min.) and (48 $\pm 7.45 \mathrm{~min}$.) respectively, with significant statistical difference $(\mathrm{P}=0.001)$. Most patients in both groups reported a mild postoperative pain, in ET group the mean percentage of patients with a mild postoperative pain was $75 \pm 1.23$, while in OT group was $80.7 \pm 1.12$, with no significant statistical difference $(\mathrm{P}=0.674)$ and the only difference reported in this regard, is the site of postoperative pain, the patients in
ET group complain of pain in the chin area, while those in OT group complain of pain in the lower cervical region.

Regarding the results of SF-36 questionnaire, the patients in ET group reported a higher rate of satisfaction scores in bodily pain (BP), social functioning (SF) and role-emotional (RE), $\quad 99.7 \pm 0.21, \quad 99.8 \pm 0.10$ and $99.6 \pm 0.13$ respectively, in comparison to $78.4 \pm 0.22, \quad 44.8 \pm 0.64$ and $77.3 \pm 0.43$ respectively for OT group with a significant statistical difference $(\mathrm{p}=0.019$, 0.001 and 0.001 respectively). Table II shows the details of the outcome of both procedures. 
Table II: The outcome of both procedures.

\begin{tabular}{|l|l|l|l|}
\hline Outcome factors & ET group (N=24) & OT group (N=26) & P-Value \\
\hline $\begin{array}{l}\text { Mean duration of surgery } \\
\text { (minute) } \pm \text { SD }\end{array}$ & $93 \pm 8.34$ & $48 \pm 7.45$ & 0.001 \\
\hline $\begin{array}{l}\text { Mean duration of hospital } \\
\text { stay (hr) } \pm \text { SD }\end{array}$ & $24.27 \pm 1.64$ & $23.82 \pm 1.87$ & 0.350 \\
\hline \multicolumn{4}{|l|}{ Visual analogue scale (VAS) (mean patients\% \pm SD) } \\
\hline No pain & 0 & 0 & \\
Mild pain & $75 \pm 1.23$ & $80.7 \pm 1.12$ & 0.674 \\
Moderate pain & $25 \pm 1.23$ & $19.3 \pm 1.12$ & 0.674 \\
(given Tramadol 50mg) & 0 & 0 & \\
Sever pain & $99.7 \pm 0.21$ & $78.4 \pm 0.22$ & 0.019 \\
\hline Mean score of SF-36 questionnaire (score 0-100) SD & 0.001 \\
\hline SF-36 BP & $99.8 \pm 0.10$ & $44.8 \pm 0.64$ & 0.001 \\
SF-36 SF & $99.6 \pm 0.13$ & $77.3 \pm 0.43$ & 1.000 \\
SF-36 RE & $99.2 \pm 0.34$ & $99.1 \pm 0.39$ & 1.000 \\
SF-36 PF & $99.1 \pm 0.31$ & $99.2 \pm 0.12$ & 1.000 \\
SF-36 GH & $99.7 \pm 0.01$ & $99.5 \pm 0.34$ & 1.000 \\
SF-36 VT & $99.4 \pm 0.18$ & $99.2 \pm 0.63$ & \\
SF-36 MH & S
\end{tabular}

Abbreviations: BP, bodily pain. SF, social functioning. RE, role-emotional. PF, physical functioning. GH, general health. VT, vitality. MH, mental health.

Regarding the complications, 2 cases of temporary recurrent laryngeal nerve palsy were reported in this study, $1(4.16 \%)$ case in ET group and $1(3.84 \%)$ case in OT group, with no significant statistical difference $(\mathrm{P}=1.000)$. both of these cases treated conservatively and resolved completely within 8 weeks. Other reported complications in this study which were unique for ET group, these were temporary mental nerve palsy in 1 case $(4.16 \%$,$) \quad which treated$ conservatively and resolved completely within few weeks, cervical subcutaneous emphysema in 1 case $(4.16 \%$,$) , this case$ also treated conservatively and resolved completely within 24 hours, another unique complication for ET group was the conversion to open thyroidectomy in 1 case $(4.16 \%$,) due to uncontrolled intraoperative bleeding. Other complications, like seroma, hematoma, permanent recurrent laryngeal nerve palsy, permanent mental nerve palsy, hypocalcemia, mediastinal emphysema and postoperative bleeding or mortality were not reported in this study.

\section{Discussion}

All patients in this study were females with unilateral benign uncomplicated thyroid pathology and all patients who were selected for TOETVA procedure were young, normal BMI and most of them have right thyroid nodule with mean size (3.6 \pm 0.443$)$. These patients' characteristics go with the published selection criteria for beginner TOETVA surgeon to avoid complications ${ }^{21}$.

Regarding the outcome of both procedures, ET group had a significantly longer operative time, this may because of the extra time needed to create the working space and port insertion and because of the narrow working space, the operation was more difficult. Most other studies comparing ET and OT had similar results $^{22-25}$. This longer operative time may decrease after a learning curve ${ }^{26-28}$. Although most studies that compare 
TOETVA to open thyroidectomy and to other endoscopic thyroidectomy approaches reported less postoperative pain in TOETVA patients ${ }^{29-34}$. In our study, we reported same level of postoperative pain in both groups, but there is difference in the site of the pain, TOETVA patients complained of pain in the upper aspect of the neck whereas patients operated upon with open thyroidectomy procedure complained of pain at the lower aspect of the neck. This result was similar to the result reported by Jonathon et $\mathrm{al}^{35}$.

Regarding patient's satisfaction after surgery, patients operated with TOETVA procedure reported better satisfaction in comparison to patients operated with open procedure. The conventional incision used for open thyroidectomy yields a very exposed surgical site, and can result in cosmetically unfavorable outcome which may lead to social and emotional disturbance in addition to the pain and itching resulted from any surgical scar. Our results goes with results of several studies that were conducted in an effort to address the issue of visible scars left by open and endoscopic techniques ${ }^{36-38}$.

Regarding postoperative complications, recurrent laryngeal nerve injury remains the most fearful complications of thyroid surgery ${ }^{39}$. In our study we reported same incidence of recurrent laryngeal nerve palsy in both procedures which goes with the results of the systemic review published by Camenzuli et $\mathrm{al}^{17}$.

Conclusion; TOETVA is a safe and feasible procedure with an excellent cosmetic outcome and better patients' satisfaction. At present, it is a relatively time-consuming procedure and therefore, candidate patients with a strong motivation for scar free surgery are recommended.

\section{References}

1. Hegedus L. The thyroid nodule. N. Engl. J. Med. 2004;351:1764-1771. doi: 10.1056/NEJMcp031436. [PubMed] [CrossRef] [Google Scholar]

2. Tan G.H., Gharib H. Thyroid incidentalomas: Management approaches to nonpalpable nodules discovered incidentally on thyroid imaging. Ann. Intern. Med. 1997;126:226-231. doi: 10.7326/0003-4819-126-3-19970201000009. [PubMed] [CrossRef] [Google Scholar]

3. Jemal A., Siegel R., Xu J., Ward E. Cancer statistics, 2010. CA Cancer J. Clin. 2010;60:277-300. doi: 10.3322/caac.20073. [PubMed] [CrossRef] [Google Scholar]

4. Haugen BR, Alexander EK, Bible KC, Doherty GM, Mandel SJ, Nikiforov YE, et al. 2015 American Thyroid Association Management Guidelines for Adult Patients with Thyroid Nodules and Differentiated Thyroid Cancer: The American Thyroid Association Guidelines Task Force on Thyroid Nodules and Differentiated Thyroid Cancer. Thyroid 2016; 26:1-133. https://doi.org/10. 1089/thy.2015.0020.

5. Kostoglou-Athanassiou I. Indications for surgical treatment in benign thyroid disease. Hellenic Journal of Surgery 2015;87:18-23. doi:10.1007/s13126-015-0173-x.

6. Tan CT, Cheah WK, Delbridge L "Scarless" (in the neck) endoscopic thyroidectomy (SET): an evidence-based review of published techniques. World J Surg 2008;32(7): 1349-1357.

7. Arora A, Swords C, Garas G, et al. The perception of scar cosmesis following thyroid and parathyroid surgery: A prospective cohort study. Int J Surg 2016;25:38-43.

8. Gagner M. Endoscopic subtotal parathyroidectomy in patients with primary hyperparathyroidism. $\mathrm{Br} \mathrm{J}$ Surg. 1996;83:875. doi: 10.1002/bjs.1800830656.

9. Ikeda Y, Takami H, Sasaki Y, Takayama J, Kurihara H. Are there significant benefits of minimally invasive endoscopic thyroidectomy? World J Surg. 2004;28:1075-1078. doi: 10.1007/s00268-004-7655-2. [PubMed] [CrossRef] [Google Scholar]

10. Inabnet WB, III, Gagner M. Endoscopic thyroidectomy. J Otolaryngol. 2001;30:41-42. doi: 10.2310/7070.2001.20932. [PubMed] [CrossRef] [Google Scholar]

11. Ikeda Y, Takami H, Sasaki Y, Niimi M. Endoscopic neck surgery by the axillary approach. J Am Coll Surg. 2000;191:336-340. doi: 10.1016/S1072-7515(00)00342-2. [PubMed] [CrossRef] [Google Scholar]

12. Witzel K, von Rahden BH, Kaminski C, et al. Transoral access for endoscopic thyroid resection. Surg Endosc 2008;22:1871-5.

13. Wilhelm T, Metzig A. Endoscopic minimally invasive thyroidectomy (eMIT): a prospective proof-of-concept study in humans. World J Surg 2011;35:543-51.

14. Nakajo A, Arima H, Hirata M, et al. Trans-Oral Video- Assisted Neck Surgery (TOVANS). A new transoral technique of endoscopic thyroidectomy with gasless premandible approach. Surg Endosc 2013;27:1105-10.

15. Wang C, Zhai H, Liu W, et al. Thyroidectomy: a novel endoscopic oral vestibular approach. Surgery 2014;155:33-8. 
16. Anuwong A. Transoral Endoscopic Thyroidectomy Vestibular Approach: A Series of the First 60 Human Cases. World J Surg 2016;40:491-7.

17. Camenzuli C, Wismayer PS, Agius JC. Transoral Endoscopic Thyroidectomy: A Systematic Review of thePractice So Far. JSLS : Journal of the Society of Laparoendoscopic Surgeons 2018;22. doi:10.4293/jsls.2018.00026.

18. Anuwong A, Kim HY, Dionigi G. Transoral endoscopic thyroidectomy using vestibular approach: updates and evidences.Gland Surg 2017; 6: 277-84. [CrossRef]

19. Dionigi G, Tufano RP, Russell J, Kim HY, Piantanidia E, Anuwong A. Transoral thyroidectomy: advantages and limitations. J Endocrinol Invest 2017 Apr. doi: 10.10007s40618-017-0676-0 [Epub ahead of print].

20. 36-Item Short Form Survey from the RAND Medical Outcomes Study. RAND Corporation. https://www.rand.org/health-care/surveys_tools/mos/36-item-short-form.html (accessed October 20, 2019).

21. Fama F, Zhang D, Pontin A, Makay Ö, Tufano RP, Kim HY, et al. Patient and Surgeon Candidacy for Transoral Endoscopic Thyroid Surgery. Turk Arch Otorhinolaryngol 2019; 10.5152/ tao.2019.18191.

22. Anuwong, A., Ketwong, K., Jitpratoom, P., Sasanakietkul, T., \& Duh, Q. Safety and Outcomes of the Transoral Endoscopic Thyroidectomy Vestibular Approach. JAMA Surgery, 2018;153(1), 21. doi:10.1001/jamasurg.2017.3366 22. Park KN, Jung CH, Mok JO, Kwak JJ, Lee SW.Prospective comparative study of endoscopic via unilateral axillobreast approach versus open conventional total thyroidectomy in patients with papillary thyroid carcinoma. Surg Endosc. 2016;30 (9):3797-3801.

23. Kim SK, Kang SY, Youn HJ, Jung SH. Comparison of conventional thyroidectomy and endoscopic thyroidectomy via axillo-bilateral breast approach in papillary thyroid carcinoma patients.Surg Endosc. 2016;30(8):3419-3425.

24. Wang YC, Zhu JQ, Liu K, et al. Surgical outcomes comparison between endoscopic and conventional open thyroidectomy for benign thyroid nodules. J Craniofac Surg. 2015;26(8): e714-e718.

25. Kadem, S. G., Habash, S. M., \& Jasim, A. H. (2019). Transoral endoscopic Thyroidectomy Via Vestibular approach: A series of the first ten cases in Iraq. Sultan Qaboos University Medical Journal [SQUMJ], 19(1), 68. doi:10.18295/squmj.2019.19.01.013

26. Liao HJ, Dong C, Kong FJ, Zhang ZP, Huang P, Chang S. The CUSUM analysis of the learning curve for endoscopic thyroidectomy by the breast approach. Surg Innov. 2014;21(2):221-228

27. Liang J, Hu Y, Zhao Q, Li Q. Learning curve for endoscope holder in endoscopic thyroidectomy via complete areola approach: a prospective study. Surg Endosc. 2015;29(7):1920-1926.

28. Kwak HY, Kim SH, Chae BJ, Song BJ, Jung SS, Bae JS. Learning curve for gasless endoscopic thyroidectomy using the trans-axillary approach: CUSUM analysis of a single surgeon's experience. Int J Surg. 2014;12(12):12731277.

29. Ikeda Y, Takami H, Niimi M, Kan S, Sasaki Y, Takayama J. Endoscopic thyroidectomy and parathyroidectomy by the axillary approach: a preliminary report. Surg Endosc. 2002;16(1):92-95.

30. Sasaki A, Nakajima J, Ikeda K, Otsuka K, Koeda K, Wakabayashi G. Endoscopic thyroidectomy by the breast approach: a single institution's 9-year experience.World J Surg. 2008r;32(3):381-385.

31. Choe JH, Kim SW, Chung KW, et al. Endoscopic thyroidectomy using a new bilateral axillo-breast approach.World J Surg. 2007;31(3):601-606.

32. Lee KE, Kim E, Koo H, Choi JY, Kim KH, Youn YK. Robotic thyroidectomy by bilateral axillo-breast approach: review of 1,026 cases and surgical completeness. Surg Endosc. 2013;27(8):2955-2962.

33. Kang SW, Lee SC, Lee SH, et al. Robotic thyroid surgery using a gasless, transaxillary approach and the da Vinci S system: the operative outcomes of 338 consecutive patients. Surgery. 2009;146(6): 1048-1055.

34. Terris DJ, Singer MC, SeybtMW. Robotic facelift thyroidectomy: patient selection and technical considerations. Surg Laparosc Endosc Percutan Tech. 2011;21(4):237-242.

35.Jonathon O. Russell,1 Christopher R. et al. Transoral Vestibular Thyroidectomy: Current State of Affairs and Considerations for the Future. J Clin Endocrinol Metab, September 2019, 104(9):3779-3784

36.Materazzi G, Fregoli L, Manzini G, Baggiani A, Miccoli M, Miccoli P. Cosmetic result and overall satisfaction after minimally invasive video-assisted thyroidectomy (MIVAT) versus robot-assisted transaxillary thyroidectomy (RATT): a prospective randomized study. World J Surg. 2014; 38:1282-1288

37.Jeong JJ, Kang SW, Yun JS, Sung TY, Lee SC, Lee YS, et al. Comparative study of endoscopic thyroidectomy versus conventional open thyroidectomy in papillary thyroid microcarcinoma patients. J Surg Oncol. 2009;100:47780 .

38. Kim, H. Y., Kim, H. S., Kim, H. I., Park, J. H., \& Yi, H. S. Scar formation and patient satisfaction after thyroidectomy with and without surgical drains. International Surgery Journal,2019; 6(8), 2692. doi:10.18203/23492902.isj20193309.

39. Hayward, N. J., Grodski, S., Yeung, M., Johnson, W. R., \& Serpell, J. Recurrent laryngeal nerve injury in thyroid surgery: A review. ANZ Journal of Surgery, 2012; 83(1-2), 15-21. doi:10.1111/j.1445-2197.2012.06247.x 